\title{
The Study on Opportunities and Challenges of Productive Safety Net Program/PSNP/ in Southern Ethiopia: A Case Study of Three Selected Woreda's in Wolaita Zone
}

\author{
Samuel Semma Waje \\ Wolaita Zone Food Security Department
}

\begin{abstract}
The study discussed the opportunities and challenges of Productive Safety Net Programme in three selected districts in Wolaita zone, Ethiopia. The study utilized cross sectional survey research design to attain the objectives. Primary and secondary data were used and analyzed by using SPSS, version 20. Sample size determined by using Cochran formula (Cochran 1963:75) and 374 households selected using multistage sampling techniques. According to the study, the major opportunities of the programme to poor households are saving life of poor households, economic changes at household and community level, the changes in social inclusion, gender equality and community health and nutrition. The key challenges of the PSNP are targeting, cash transfer problems, and low economy base of the poor households, low graduation performance and weak management of appeals. The study proposed the way forward to enhance the opportunities and to minimize the challenges faced at the implementation stage of the programme.
\end{abstract}

Keywords: Opportunities, Challenges, Productive safety net

DOI: $10.7176 / \mathrm{DCS} / 10-4-02$

Publication date: April $30^{\text {th }} 2020$

\section{Background}

Following the drought of 2002/2003, the Government of Ethiopia formed the New Coalition for Food Security to identify key actions to break the cycle of emergency appeals, which saved lives but did little to protect household assets-and comprehensively address food insecurity in Ethiopia.The Ethiopian government initiated to launch the Productive Safety Net Programme in 2005 for the goal of helping chronically food-insecure households to withstand with stresses and shocks, accumulate and create an asset and to make them food self-sufficient. The Productive Safety Net Programme (PSNP) is Ethiopia's rural safety net for food insecure households. The programme covers households in Afar, Amhara, Dire Dawa, Harari, Oromiya, Southern Nations, Nationalities and Peoples (SNNP), Somali and Tigray, and targets households that are chronically and transitorily food insecure. The programme provides cash and/or food transfers to these households based on need and season either through direct support or public work activities. Households that have able-bodied adult labour engage in public works and receive transfers for 6 months of the year. Households without labor capacity, permanent direct support clients, receive 12 months of unconditional transfers and are linked with social protection services. (MOARD, 2014)

The programme provides technical assistance and training in livelihood activities (crop and livestock, offfarm, and employment) to clients to enable households to increase and diversify their incomes and build their assets. While many clients who participate in livelihoods activities are referred to credit providers, for the poorest households, the programme provides livelihood transfers that do not need to be repaid, helping them build their assets more rapidly while avoiding a cycle of indebtedness. Together, these interventions aim to strengthen resilience, improve nutrition, and help households become food sufficient and, eventually, food secure. The Achievement of food security is an emergent challenge in developing African countries. The wellbeing of human beings such as poor people's health and education, their ability to work, human right and equality are harmed by the problem of food insecurity. Children's, girls and women are the most vulnerable to the shocks of food insecurity. (Mohamed, A.A., 2017)

\subsection{Statement of the problem}

Eighty five percent of peoples of Ethiopia live in rural areas and depend on agriculture. Agriculture accounts $39 \%$ of the Ethiopian GDP and employing 73 percent of the working population. Most of the Ethiopian people are traditional farmers. The Ethiopian government has adopted the policy measurement to transform the agricultural sectors and initiated the Productive Safety Net Programme (PSNP) is Ethiopia's rural safety net for food insecure households. The programme supports the Ethiopian government major policy frame works mainly Growth \& Transformation Plan (GTP2), the Social Protection Policy, the National Policy and Strategy on Disaster Risk Management (NPSDRM), the National Nutrition Programme (NNP), the Climate Resilient Green Economy (CRGE) The programme covers households in Afar, Amhara, Dire Dawa, Harari, Oromiya, Southern Nations, Nationalities and Peoples (SNNP), Somali and Tigray, and targets households that are chronically and 
transitorily food insecure. The programme provides cash and/or food transfers to these households (MOArd, 2014).

The food security problem in Ethiopia has been outsized degree which was addressed by annual emergency food aid from different worldwide development agencies. Nowadays Ethiopia has more than 10 million poorest household across the country those who need both chronic and temporal food insecurity (World Bank Report 2018). The fundamental reason behind the program was to provide cash for food insecure people with direct support beneficiaries and public work during agricultural slack seasons, in doing so preventing them from selling productive assets and enhancing their livelihoods. (Andersson, Mekonnen et.al, 2011)

Donors and the government of Ethiopia agreed to involve for the success of the program to attain its objectives. While entering into the implementation stage, the programme encountered some factors affect the implementation of the program. The factors that hampered the program were capacity, ideologies of graduation and dependency and timeliness of transfers and donor funding (Brown and Teshome, 2007). In the same idea Fiseha 2014 explained the other problem or challenge that faces implantation of the program was inadequate financial resources. As result, a small number of beneficiaries were allowed to participate in the program. According to Mohamed (2017), accessibility of assets has influence on the government strategies to be under taken. Besides, study results indicate that geographical location, administrative (selection mechanism used for eligible household), and exclusion of poor with inclusion of rich, weak institutional linkages and lack of active community participation in the decision making process were the challenges for the program (Fekadu and Ignatius, 2009).

According to the Teshome (2013), some of the challenges of the program were targeting of beneficiaries and inability to distinguish between acute and chronic food insecurity at grassroots level, application of single wage rate at national level, lack of the capacity to manage, unprecedented amount of cash flowing into the district and linkage problem at grassroots level. The challenges that face PSNP implementation were inclusion and exclusion of beneficiaries, poor conservation, and limitation of awareness of beneficiaries, linkage problem of officials, lack of manpower in remote areas, lack of monitoring and evaluation of locally constructed infrastructures for their sustainability (Welteji et al., 2017).

Wolaita Zone is one of implementing zone of Ethiopian productive safety program in Southern Ethiopia; the numbers of total clients in the zone are 199,999. But the implementation of Productive Safety net program has its own opportunities and challenges. (Wolaita Zone Food Security Department, 2016)

The major opportunities of this programme are labor based humanitarian aid (direct and public works transfers); the program beneficiaries encompass access of getting money by participating in public work projects such as Water shade development management, community development projects such as sustainable land management, small rural road constructions, and capital budget projects such as community pond development, Farmers training centers (FTCs) developments, small Water spring developments works, ,School maintenance and Health post construction are the major opportunities of the program in wolaita the zone. The program has also other opportunities in order to change poor households' livelihood. These are access to get finance through MFIs, RUSSACOs and VSLAs, ease of doing rural business through prepared income generating activities/IGAs), Skill training to poor households on Business plan, financial management, are the major opportunities of the programme in the zone.

Major Challenges of the programme implementation includes weak targeting system, payment problems (timeliness, unknown deductions), low level of graduation, and attitudes for adaptation of poverty on poor households due to low economy bases and less using appeal request system and its management. This study was designed to assess the opportunities and challenges of the productive Safety Net Programme in three selected districts in Wolaita zone, Ethiopia.

\subsection{Objectives}

\subsubsection{General objectives}

The general objective of this study is to identify the opportunities and challenges of productive safety net programme in Wolaita zone, Ethiopia.

\subsubsection{Specific objectives}

1. To examine the socio-economic attributes of poor households in the area

2. To identify major opportunities of the Productive Safety Net Program in the area

3. To identify major challenges of the Productive Safety Net Program in the area

\subsection{Scope of the Study}

The study covers the area of southern Ethiopia, Wolaita zone, three districts namely Sodo zuria ,Damot gale and Boloso Sore only. The study focused on Ethiopian Productive safety Net Programme four/PSNP4/. 


\subsection{Research question}

What is the positive (opportunities) and negative (challenges) of safety net program on household and community level?

\section{Review of Literatures}

\subsection{Social Protection in Africa}

The continent Africa showed a tremendous growing for the first two decades of the new millennium transform from hopeless continent to a region with countries of fastest growing economies which resulted in reduction of poverty from 58 percent in 1995 to 48 percent in 2008 (World Bank report,2011). Many African countries initiated rural development policy which ensures social protection and enhance sustainable economic growth for their citizens (World Bank, 2012). Social protection is a program with provision of cash or in-kind transfers to the poor as means of reducing poverty and economic and social vulnerability (FAO, 2015). In general, social protection has three components such as social assistance, social insurance and labor market protection. Social assistance programs are cash or in-kind transfers or public works programs. Programs that provide cover for designated contingencies affecting household welfare or income are called social insurance programs. However, labor market programs offer unemployment benefits to the workers through building skills. Hence, it increases workers' productivity and employability (FAO, 2015). The government of the Ethiopia implements the social protection program, that is, cash or in-kind transfers or public works programs for chronically food insecure community (Care, 2014). Such type of social protection program in Ethiopia is known as PSNP (Kassa WA,2018).

Countries like Kenya developed social protections interventions which named as The Hunger and Safety Net Program of Kenya aimed at tumbling hunger and vulnerability which is targeted cash transfer mechanism for poor and vulnerable people. The program give priority to the chronically food in secured districts of Mandera, Marsabit, Turkana and Wajir districts. However, the social protection program in the country has not properly domesticated in the country's legal policy and framework and the emergency programs have been implemented in haphazard and knee-jerk approach with minimal strategic policy focus (Irungu, et.al, 2009) Ghana has a social protection program named Ghana's Livelihood Empowerment against Poverty (LEAP) which is also safety net program in western parts of the continent which offers cash and health insurance to chronically poor households to minimize short-term poverty and enhance sustainable human capital development. The program launched in June 2013, 71, 000 households are enrolled. The objective was expected to enlarge its transfer for more than 1 million Ghanaian in the next three years (World Bank, 2012)

Uganda has also social protection which has been implementing by the ministry of local government of Uganda. The program is designed for poor households and cash for work. The beneficiaries work different types of public works such as terraces, ditches, small dams as well as construction of roads, schools and health centers. The public work program was one source of livelihood for 5 percent of the country's population which composed of 522, 856 people (Devereux \& Sabates-Wheeler, 2011). Rwanda's Umurenge Program (VUP) was the other prominent social projection program with an plan to graduate households from the program at short period of time through public work, cash transfer and microfinance credit to chronically poor households in different sub districts of the country((Devereux \& Sabates-Wheeler, 2011)

\subsection{Food security in Ethiopia}

Food security in Ethiopia has long been a pervasive problem. Eighty (80) percent of the people in Ethiopia live in rural areas and majorly dependent on agriculture. The poor farmers extremely vulnerable to food gap due to changes of weather conditions. Even in years with normal rainfall, food shortages and hunger are persistent problems for millions of people. (Camilla Andersson, et.al, 2009).

There were different type's droughts and shocks occurred in Ethiopia. To see them chronologically, 2003-4, over 13 million people affected in Somali region, but the mitigated the government from the worst outcomes, 2008-09, almost 3 million people affected from pastoral areas of the country,2011-13, EL-Niño drought affected more than 27 million people but no deaths was reported(Hill and Porter, Anderson et al, 2015)

According to Ministry of Agriculture and Natural Resource Development (MOARD, 2006) food security strategy of Ethiopia which designed in 1996, highlighted in the government plan to address cause and consequence of food insecurity in Ethiopia (MOARD,1996). The strategy is mainly based on Agricultural Development Led Industrialization (ADLI) that centers creating capabilities for national food self sufficiency. Again to ensure food security to fast growing Ethiopian population, the Government of Ethiopia (GOE) collaborated with other donors drafted document poverty reduction strategy paper (PRSP) in July 2001. Drawing from the first PRSP, and aligning itself with the findings of a millennium development goal (MDG) needs assessment for Ethiopia, the government has since established the plan for accelerated and sustained development to end poverty (PASEP). The PASEDP considered as the vehicle for achievement of the MDG's and have a 5-year time frame (2005-2010) (Sharp \& Amdissa, 2006). 
According to the study of Gilligan et al. 2008, the Ethiopian government and a consortium of donors (including the World Bank, U.S. Agency for International Development, Canadian International Development Agency, and several European donors) launched a new social protection program called the Productive Safety Net Program (PSNP). With an annual budget of nearly US\$ 500 million, the PSNP is a huge program, reaching more than 7.5 million Ethiopians (Gilligan et al. 2008).

\subsection{Productive safety net and its contribution in Ethiopia.}

Scholars identified the positive and negative reflection of Productive Safety Net Program in Ethiopia, a number of studies conducted show that PSNP has a positive impact on the rural community such as Debela and Holden, 2014, Gebresilassie, 2014, Andersson et al., 2011; Mohamed, 2017 and those studies emphasized that PSNP has consequences were Mamo, 2011; Hayalu, 2014; Beshir, 2011; Gilligan et al., 2009; Sabates- Wheeler and Devereux, 2010; Adimassu and Kessler, 2013. The finding of Zoellick (2014) indicates that PSNP has positive impact through preventing households from selling productive assets; facilitating new investment, income increase, reductions in stunting and an increase in household food provisions, infrastructure as well as food security for households. Hence, it has improved food security, use of educational and health services and agricultural productivity. PSNP has positive effect on consumption, livestock holdings and productive assets of the household as indicated by Gebresilassie (2014). The participation of household in PSNP has positive and statistically significant effect on food consumption and on their livelihood (Mohamed, 2017). The PSNP has positive effect on the participant household. Therefore, that it helps beneficiaries for consumption smoothing and asset accumulation (Welteji et al., 2017). According to Debela and Holden (2014), the PSNP has positive effect on children through providing short-term nutritional benefits. However, some scholars conclude that PSNP has negative impact on the rural community (. Some of the negative consequences of the PSNP program were developing sense of dependency syndrome (Hayalu, 2014). According to Mamo (2011), household failed to enhance asset accumulation if they are incorporated under PSNP. According to the earlier researchers (Beshir, 2011; Gilligan et al., 2009; Sabates- Wheeler and Devereux, 2010), PSNP has negative effect on welfare/asset building and consumption. Adimassu and Kessler (2013) reported that PSNP has also negative effect on soil erosion control measures.

\section{Methods}

\subsection{The Study Area}

Wolaita zone is located in southern Ethiopia, between $6.4^{\circ}-7.1^{\circ} \mathrm{N}$ and $37.40^{\circ}-38.20^{\circ} \mathrm{E}$ geographical position and $360 \mathrm{Km}$ south of Addis Ababa, capital of Ethiopia. The zone is one of the thirteen zonal administrative structures in south regional state of Ethiopia, covering an area of $4471.3 \mathrm{Km}^{2}$ (BoFED, SNNPRS, 2010). The zone is divided into sixteen woredas (districts) six town administrations.

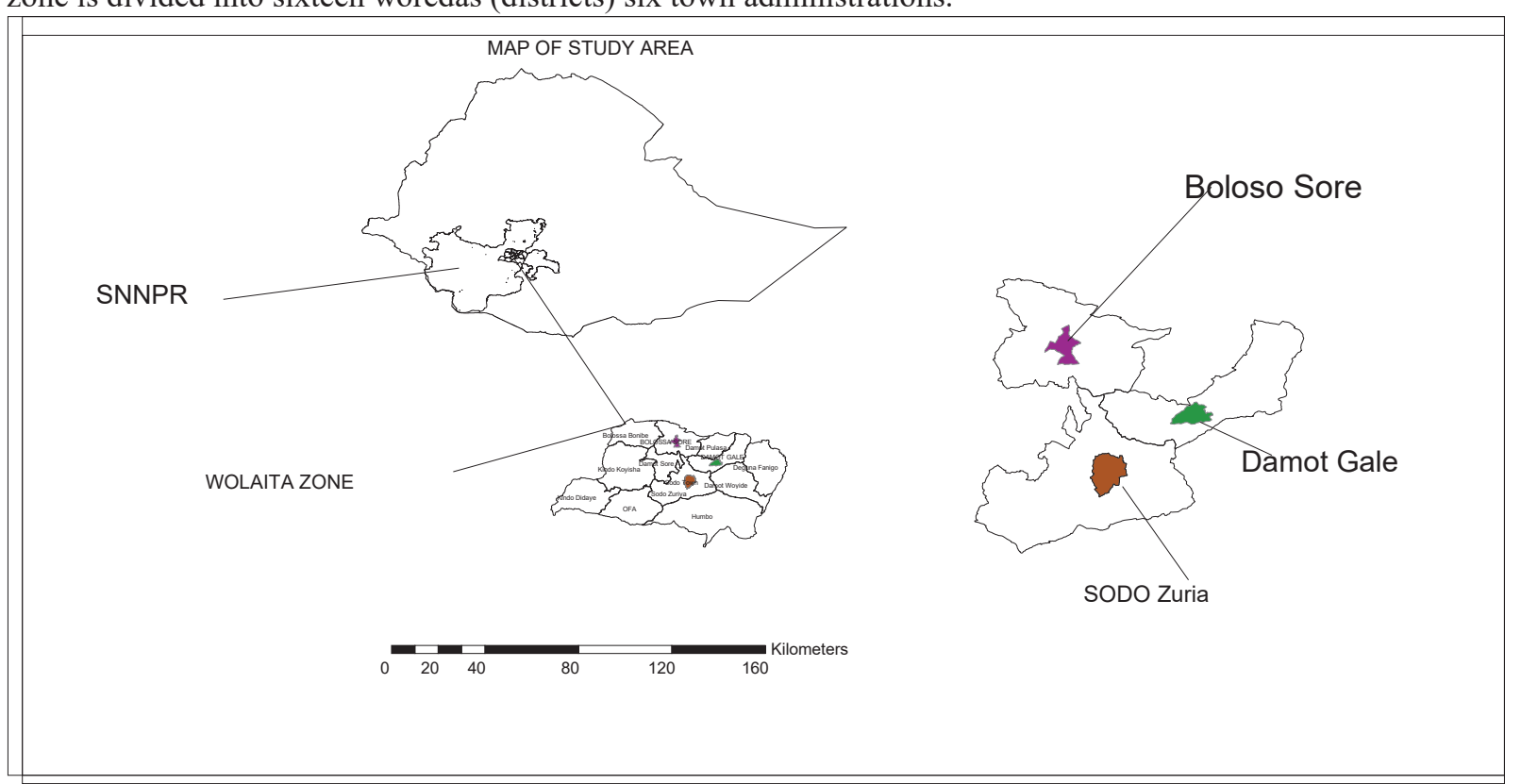

Source: Areal Map developed by the researcher: 2020

The total population of the zone is estimated about 1,907,079 with average density 385 inhabitants per square kilometers (CSA, 2017) being is one of densely populated areas in Ethiopia. 


\subsection{Research Design}

As part of the study to address the stated objectives a cross sectional household survey was used since Cross sectional survey enables to effectively manage and collect the data collection. According to LeUnes(2002), Survey study is preferable to undertake research employing large numbers of people or respondents questions their perception, characteristics and opinions towards a specific issue. Triangulation has been employed for it helps to increase the reliability of the results by comparing the data obtained from one source with the other sources.

\subsection{Target population}

The study area consists of the total population of 48,203 public work beneficiaries and 14,873 HHs in the productive safety net program /PSNP/of the three study districts. Therefore, the total population of the study covers three districts public work clients/beneficiaries/ those who are registered in the monthly payroll and attendance spread sheet (PASS).

\subsection{Sampling Design and Procedure}

This study mainly focuses on the opportunities and challenges of PSNP in rural community. The three districts (Sodo Zuria, D/Gale and B/sore) were purposely selected the study among 16 districts in the wolaita zone. The study covers different stages to collect the sample size. Due to large size area multi-stage sampling was used. Multistage sampling used because the research applied at different stages i.e. at Zone,Woreda(districts) and kebelle levels. The key challenges of the program were presented by focused group discussion members (510).Nine (9) focus group discussions (FDGs) were selected and one from each kebelle's were prepared and named by codes.

Table 3.1: Distribution of Sample size by selected woreda and kebeles

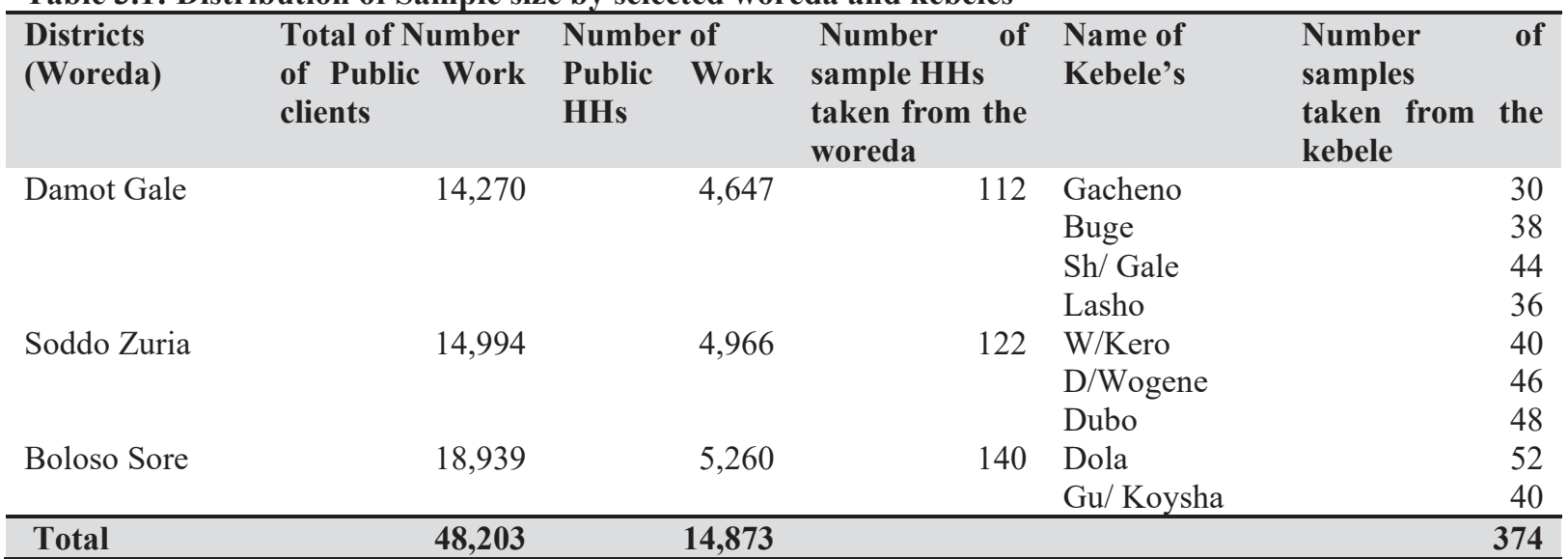

Source: drawn for the study only,2020

\subsection{Sample size}

To achieve the objectives of the study 9 (nine) kebeles were purposely chosen from the three districts. According to Cochran (1963:75) developed the equation to yield a representative sample for proportions of large sample. Since the numbers of productive safety net program clients are more than 10,000 in the three districts, we can use the sample size formula (Cochran 1963:75)

$$
\mathbf{n}_{\mathbf{o}}=\frac{\mathbf{Z}^{2} \mathbf{p q}}{\mathbf{e}^{2}}
$$

Which is valid where $n_{0}$ is the sample size, $Z^{2}$ is the abscissa of the normal curve with $95 \%$ confidence level and $5 \%$ precision e is the desired level of precision, $\mathrm{p}$ is the estimated proportion of an attribute by assuming $\mathrm{p}=.5$ (maximum variability)that is present in the population, and $\mathrm{q}$ is $1-\mathrm{p}$. The value for $\mathrm{Z}$ is 1.96 which is found in statistical tables which contain the area under the normal curve.

By using the above formula, we have;

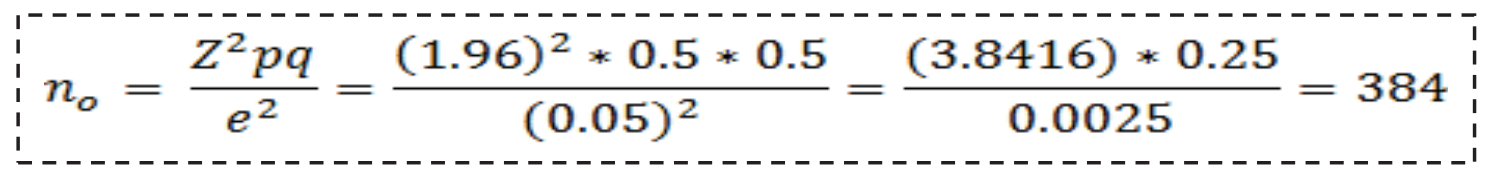

Using infinite population sample size determination formula the total numbers of samples included in the study were $=384$. Since the study targeted three districts PSNP clients, the study used finite population sample size 
determination formula (Cochran 1963:75), we have:

$\left.n=\frac{\frac{n o}{1+(n o-1)}}{N}=n=\frac{\left.\frac{384}{1+(384-1}\right)}{2975}\right)=\frac{384}{1+\frac{(383)}{14,873}}=\frac{384}{1.025}=374$

\subsection{Data types, Sources and Analysis}

The data collection method relied on primary data which has been collected mainly through FGDs, interviews and open and closed ended questionnaires. Secondary data are: program documents, manuals, reports, proclamations, profiles, and statically data and other national and international reviews. Data was analyzed by using SPSS 20 version, the responses of the participants was analyzed by using tables, frequency, percentages, mean and standard deviations.

\section{Results and Discussion}

\subsection{Questionnaire response rate}

Three hundred seventy four (374) questionnaires were distributed across the three districts. Out of which 352 were completed and retrieved successfully, representing $94.12 \%$ response rate.

\subsection{Socio - Demographic characteristics of PSNP Households}

Table 4.1. Age, Sex, and Educational, family size and farmland size status of PSNP HHs

\begin{tabular}{|c|c|c|c|}
\hline & Category & Frequency & Percent \\
\hline \multirow{5}{*}{ Age } & $25-34$ & 102 & 28.98 \\
\hline & $35-44$ & 202 & 57.39 \\
\hline & $45-60$ & 42 & 11.93 \\
\hline & Above 60 & 6 & 1.70 \\
\hline & Total & 352 & 100 \\
\hline \multirow{3}{*}{ Sex } & Male & 208 & 59.09 \\
\hline & Female & 144 & 40.91 \\
\hline & Total & 352 & 100 \\
\hline \multirow{5}{*}{ Education } & Illiterate & 152 & 43.18 \\
\hline & Primary education(Grade 1-6) & 130 & 36.93 \\
\hline & Secondary education (Grade 7-12) & 54 & 15.34 \\
\hline & College diploma & 16 & 4.55 \\
\hline & Total & 352 & 100 \\
\hline \multirow[t]{4}{*}{ Marital Status } & Married & 276 & 78.41 \\
\hline & Divorced & 32 & 9.09 \\
\hline & Widow & 44 & 12.50 \\
\hline & Total & 352 & 100 \\
\hline \multirow{4}{*}{ Family size } & $1-4$ & 102 & 28.98 \\
\hline & $4-6$ & 178 & 50.57 \\
\hline & $>6$ & $12^{`}$ & 20.45 \\
\hline & Total & 352 & 100 \\
\hline \multirow{4}{*}{ Owning farm land } & $<0.25 \mathrm{Ha}$ & 286 & 81.25 \\
\hline & $0.25-0.5 \mathrm{Ha}$ & 42 & 11.93 \\
\hline & $0.5-0.75 \mathrm{Ha}$ & 24 & 6.82 \\
\hline & Total & 352 & 100 \\
\hline
\end{tabular}

Source: Field survey: 2020

Table 4.1.represents the socio-demographic characteristics of productive safety net program beneficiaries in the three selected districts in wolaita zone, Ethiopia. Accordingly, the age of respondents from the 352 respondents, (202)57.39\% were under age group of 35-44 years, and (102)28.98\% were under age group of 2535 years. The age category under 46-60 were $11.93 \%$ and above 60 were few in number $(1.70 \%)$. From the table information, we can conclude that the major households were at the age range of 35-44(57\%) years groups and the least age is $1.7 \%$ with age range of above 60 . When we see the gender composition of the study the majority of the respondents were males $(59.09 \%)$ and the remaining $40.91 \%$ were females.

The table also presents the educational status of the poor households, $43.18 \%$ of the respondents were illiterate, $36.93 \%$ attended primary education and the remaining $15.35 \%$ and $4.55 \%$ were secondary and diploma holders respectively. The majority $(78.41 \%)$ of the respondents were married, large percentage of the households $(50.57 \%)$ hold the family size range of $4-6$, followed by the range of $1-4(29 \%)$ and $20 \%$ of the respondents have 
more than six family members. $81 \%$ of the respondents have less than 0.25 hectare farmland, $12 \%, 7 \%$ have hectares of 0.25-0.5 and 0.5- 0.75 hectares. This shows most of the poor households selected in safety net programme have less than 0.25 hectares. This data implies that low farmland is one the challenge that made them to stay at the poorness altitude.

\subsection{Analysis of Opportunities of PSNP}

This section analyzes Household and Community level Economic and Social opportunities of the productive safety net program opportunities indicators of the three selected districts in wolaita zone, Ethiopia.

4.3.1. Economic opportunities at Household level

Table 4.2: Respondents' response of change in their life on public work payments in the last five years

Have PSNP cash payment made a change your N $\quad$ Mean Standard Deviation

family life in the last five years?

\begin{tabular}{llll}
\hline Fulfill food gap and tolerate shocks & 352 & 3.88 & $\mathbf{1 . 1 0 2}$ \\
Helped to buy Clothes & 352 & 3.37 & $\mathbf{0 . 9 4 8}$ \\
Helped to change slump houses & 352 & 2.46 & $\mathbf{0 . 9 8 2}$ \\
\hline Total & & $\mathbf{3 . 2 4}$ & $\mathbf{1 . 0 1 0}$ \\
\hline
\end{tabular}

Source: Survey, 2020

Table 4.2 indicates the impact of public work payment (transfers) on their livelihood of respondents. The households were asked to explain change in their livelihoods in the last five years when they compare before and after joining to the programme. They quoted that the majority portion (mean of 3.88 and standard deviation of 1.102) of public work payments was on fulfilling food gap and tolerate shocks of their family. The total mean score of 3.24 and standard deviation of 1.010 which implies that safety net payment has immense economic opportunity for poor households to sustain their lives.

Table 4.3: Ownership of major home using equipments and Livestock before and after safety net

$\begin{array}{lll}\text { Have you fulfilled and owned the major } & \text { Before PSNP } & \text { After PSNP }\end{array}$
home using equipments?

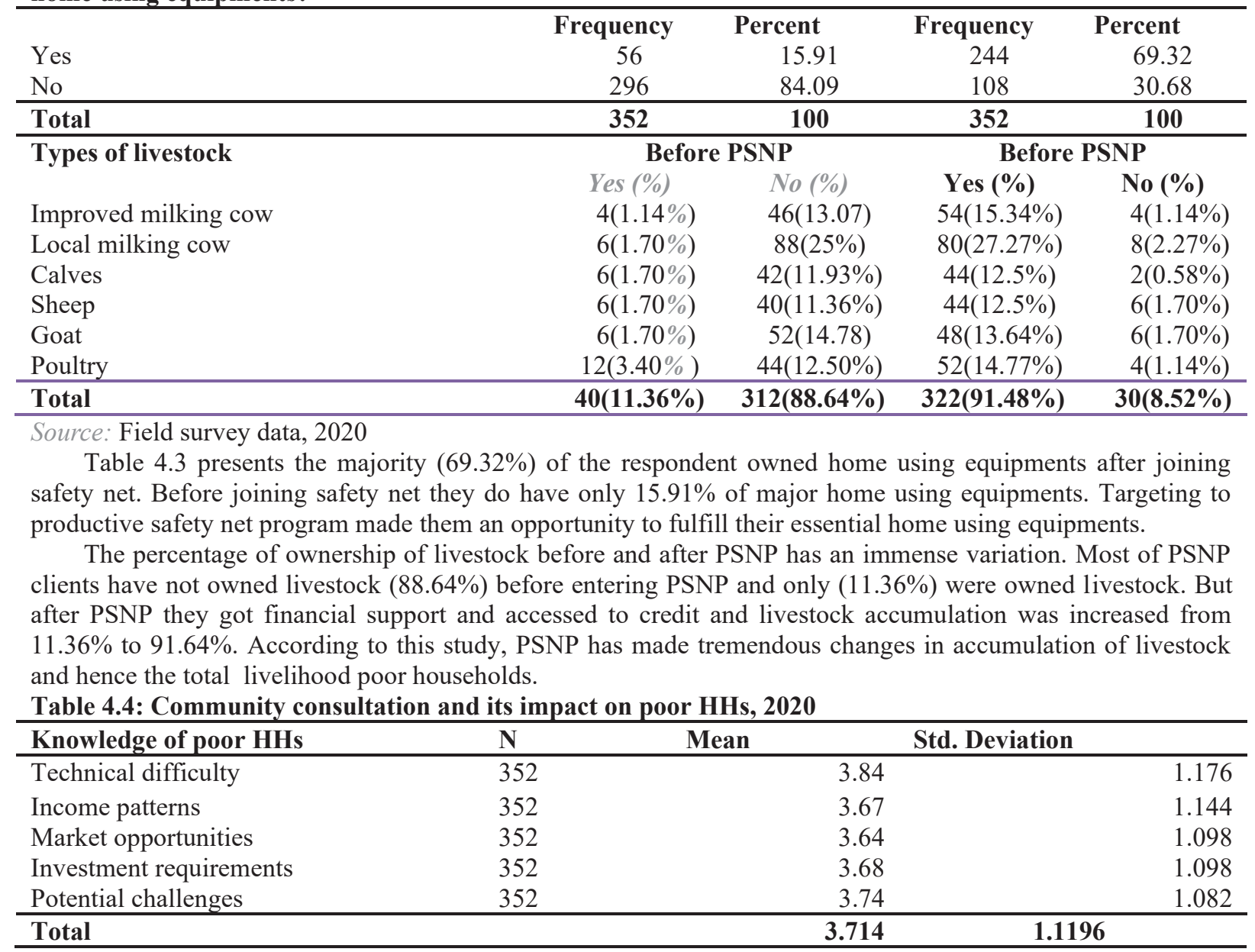

Source: field data, 2020

In order to guide clients in the selection of livelihoods that are appropriate to their capacity, client 
consultations will cover the above topics for each type of livelihood: Table 4.4 gives an overview of community consultation its impact on poor households. Accordingly, the technical difficulty of poor household holds with mean and standard deviation 3.84 and 1.176 respectively. This indicates that technical difficulty has great influence on poor food insecure households. On the same manner they face with many potential challenges that occurring daily with mean and standard deviation 3.74 and 1.082 respectively. Understandings of income patterns, knowledge to market opportunities and investment requirements increased with mean/ standard deviation of 3.67/1.144,3.64/1.098, 3.68/1.098.

Table 4.5: Type of financial literacy training given for beneficiaries of PSNP

\begin{tabular}{lcrr}
\hline Types of fin literacy training & N & Mean & Standard Deviation \\
\hline Cash and financial management & 352 & 3.87 & 1.112 \\
Financial planning and budgeting & 352 & 3.66 & 1.037 \\
Savings - the importance of savings, and how to save & 352 & 3.80 & 1.138 \\
Understanding credit & 352 & 3.70 & 1.140 \\
Calculating profits & 352 & 3.47 & 1.192 \\
Risk management and insurance & 352 & 3.87 & 1.012 \\
\hline Total & & $\mathbf{3 . 7 3}$ & $\mathbf{1 . 1 2 3}$ \\
\hline
\end{tabular}

Source: Field data, 2020

From Table 4.5 we can refer that both cash management and risk management and insurance have equal mean of 3.87 and their standard deviation of 1.112 and 1.012. On the other hand, the beneficiaries were trained about financial planning and budgeting, saving and its importance, how to calculate the profits, increased the understanding about credit. In general training is one the biggest opportunity to the poor households to change their livelihoods.

Table 4.6: Credit Access by MFIs and RUSSACOs by per HHs

\begin{tabular}{lrrrr}
\hline Types of Asset building Activities & Before safety net & \multicolumn{2}{c}{ After safety net } \\
\hline & Frequency & Percent & Frequency & Percent \\
Access to credit by MFIs & 42 & 11.93 & 142 & 40.34 \\
Access to credit by RUSSACOs & 24 & 6.81 & 180 & 51.14 \\
Access to credit by VSLAs & 0 & 0 & 30 & 8.52 \\
\hline Total & $\mathbf{6 6}$ & & $\mathbf{3 5 2}$ & $\mathbf{1 0 0 . 0 0}$ \\
\hline
\end{tabular}

Source: field survey, 2020

Access to credit to the clients in microfinance institutions increased from 11.93 percent to 40.34 percent. This refers poor productive safety nets clients were not accessed to credit before they join to the progrmme and on contrary to this, after entering into productive safety net their opportunity to credit by microfinance was increased by $40.34 \%$. Equivalently Rural Saving and Credit Organizations (RUSACOs) provided a few credit $(6.8 \%)$ to clients before they entered into safety net programme and after the clients were being member of safety net program, access to credit brought a significant change (51.14\%). Village Saving and Loan Associations were not allowing the poor's to access credit $(0 \%)$ before PSNP, this is because the VSLAs has assumption of poor HHs do not have ability to repay the loans. Oppositely, after PSNP membership 30(8.52\%) beneficiaries were accessed credit from VSLAs. Comparing the three financial institutions in the area accessing credit to poor households, RUSSACOs performs better according to this study (51\%).

Table 4.7: Saving culture of the HHs before and after Productive Safety Net Program

\begin{tabular}{lcccc}
\hline Institutions & Before PSNP & \multicolumn{3}{c}{ After PSNP Change } \\
\hline & Yes & No & Yes & No \\
Microfinance's & 19 & 102 & 98 & 10 \\
RUSSACOs & 27 & 114 & 136 & 8 \\
VSLAs & 0 & 90 & 96 & 4 \\
\hline Total & $\mathbf{4 6}$ & $\mathbf{3 0 6}$ & $\mathbf{3 3 0}$ & $\mathbf{2 2}$ \\
\hline
\end{tabular}

Source: Field survey data, 2020

Table 4.7 shows comparison of saving culture before and after PSNP. Before Safety net, almost all respondents said 'yes' or not created a culture were (3.4\%) in microfinance's, $5.7 \%(20)$ in RUSACOs, and $(0 \%)$ in VSLAs. On contrary to this, the saving culture of the respondents was increased, (from $3.4 \%$ to $27.84 \%$ ) in Microfinance's, (from 5.7\% to 38.63\%) in RUSACOs, and from $0 \%$ to $27.27 \%$ ). The reason behind this is the program gave tremendous training packages as it indicated in table 9 for the poor households. According to the findings of this study, the saving culture of the PSNP members increased and this could be explained as one of great opportunity for poor households to transform from food insecurity to food security. 
Table 4.8: Accumulation of Assets in ET Birr

\begin{tabular}{lll}
\hline Accumulated asset value in ET Birr & Frequency & Percent \\
\hline $2000-3000$ & 88 & 25.00 \\
$3001-4000$ & 102 & 28.98 \\
$4001-5000$ & 86 & 24.43 \\
$5001-6000$ & 60 & 17.04 \\
$>6000$ & 16 & 4.55 \\
\hline
\end{tabular}

Source: survey report, 2020

Table 4.8 presents the total assets accumulated in Ethiopia Birr (ETB) and the assets were not include the livestock's and major home using equipments and its only of the amount of money that they have on their hand(pocket). $25 \%$ of the participants were accumulated the range of $2000-3000 \mathrm{ETB}, 28.98 \%$ of the respondents accumulated a wealth of $3001-4000 \mathrm{ETB}, 24.43 \%$ of the respondents accumulated a wealth of 4001- 5000 ETB, $17.04 \%$ of the respondents accumulated a wealth of 5001-6000 ETB only 4.55\% of the participants accumulated ETB more than 6000. The table also indicates that large portion of the participants (53.41\%) were accumulated ETB 3001-5000. Even though the accumulated amount was not enough to graduate from food security, but it counted as one of the opportunity for poor households it has own shares to transform the rural community.

4.4. Economic Opportunities at community level

Table 4.9: Perceptions of the respondents about change in Community

\begin{tabular}{lcc}
\hline Is PSNP public work activities changed your community really? & Frequency & Percent \\
\hline Yes & 300 & 85.22 \\
No & 41 & 11.65 \\
I don't know & 11 & 3.13 \\
\hline Total & $\mathbf{3 5 2}$ & $\mathbf{1 0 0 . 0 0}$ \\
\hline
\end{tabular}

Source: Field data, 2020

Table 4.9 presents the perception of poor households about the community changes of the program in their local area. $85 \%$ of the participants' perception indicates that the community was absolutely PSNP has been made a great change to their community.

Table 4.10: Major Integrated community-based projects of PSNP (2016-2020)

\begin{tabular}{|c|c|c|c|c|c|c|c|c|c|c|}
\hline $\begin{array}{l}\text { Types of projects } \\
\text { constructed by PSNP }\end{array}$ & $\begin{array}{l}\text { Uni } \\
\text { ts }\end{array}$ & & Ta & ets & & & $\overline{\text { Achie }}$ & ments & & $\begin{array}{l}\text { Percent } \\
\text { s }\end{array}$ \\
\hline & & $\begin{array}{l}\text { S/Zuri } \\
\text { a }\end{array}$ & $\begin{array}{l}\mathrm{B} / \\
\text { Sore }\end{array}$ & $\begin{array}{c}\mathrm{D} / \mathrm{Gal} \\
\mathrm{e}\end{array}$ & Total & $\begin{array}{c}\text { S/Zuri } \\
\text { a }\end{array}$ & $\begin{array}{c}\mathrm{B} / \\
\text { Sore }\end{array}$ & $\begin{array}{c}\mathrm{D} / \mathrm{Gal} \\
\mathrm{e}\end{array}$ & Total & \\
\hline $\begin{array}{l}\text { Community } \\
\left(5000 \mathrm{~m}^{3}\right)\end{array}$ & № & 10 & 9 & 12 & 31 & 9 & 9 & 10 & 28 & 90.32 \\
\hline local road construction & $\mathrm{Km}$ & 20 & 15 & 16 & 51 & 16 & 15 & 15 & 46 & 90.20 \\
\hline $\begin{array}{lr}\text { Farmers } & \text { training } \\
\text { Centers } & \text { Construction } \\
\text { (FTC) } & \end{array}$ & № & 8 & 6 & 8 & 22 & 8 & 6 & 8 & 22 & 100.00 \\
\hline $\begin{array}{l}\text { Agricultural inputs } \\
\text { warehouses } \\
\text { construction }\end{array}$ & No & 4 & 3 & 4 & 11 & 2 & 3 & 3 & 8 & 80.00 \\
\hline Health Post centers & № & 2 & 1 & 2 & 5 & 2 & 1 & 2 & 5 & 100.00 \\
\hline $\begin{array}{l}\text { School classroom } \\
\text { expansion }\end{array}$ & No & 10 & 12 & 12 & 34 & 8 & 8 & 9 & 25 & 73.50 \\
\hline Total & & 54 & 46 & 54 & 154 & 45 & 42 & 47 & 134 & 87.01 \\
\hline
\end{tabular}

Source: Achievement report, WZFSD, 2020

Productive safety net program has an objective of rehabilitating the community by constructing community based projects which are the planned and prioritized by the community. This study analyzed the capital budget performances of the three districts during the five years from 2015/16-2019/20.Accodngly, 90.32\% of community ponds $\left(5000 \mathrm{~m}^{3}\right)$ achieved, the community pond is very important to drink cattle's at the season of winter (Bega) time of less rain and help youth groups as irrigation source to produce agricultural inputs, $90.20 \%$ of local small road construction, in which the community using day to day activities. $100 \%$ of farmers training center (FTC) achieved which is very important to farmers in near area(kebele level), 80\% agricultural inputs storing warehouse construction was achieved, $100 \%$ health post construction and $73.5 \%$ of school expansion activities have been performed in the programme. The table 4.10 shows the integrated community-based projects 
built by the Productive Safety Net Program. This can be seen as good economic opportunity that fundamentally helps the community in three districts in wolaita zone.

\subsection{Social opportunities of PSNP}

Table 4.11: Social inclusion of poor HHs to the society

\begin{tabular}{lccc}
\multicolumn{1}{c}{ Item } & N & Mean & \multicolumn{1}{c}{ Standard deviation } \\
\hline PSNP helped to participate in social community events & 352 & 3.22 & 0.924 \\
such as funeral, kebele meeting etc & & & \\
PSNP reduced social discriminations & 352 & 3.02 & 0.896 \\
PSNP created a capacity build social equity & 352 & 4.02 & 1.002 \\
PSNP helped to drop out from local informal creditors & 352 & 3.81 & 0.988 \\
\hline Total & & $\mathbf{3 . 5 2}$ & $\mathbf{0 . 9 5 2}$ \\
\hline
\end{tabular}

Source: field data, 2020

One of the objectives of Productive Safety Programme is to see all Ethiopians enjoy social and economic well-being, security and social justice. According to table 4.11 the respondents emphasized that PSNP helped them to participate in social community events such as funeral, kebele meeting with the mean of 3.22 and standard deviation of 0.924 . Moreover, as they replied PSNP created a capacity to build social equity with the highest mean and standard deviation of 4.02 and 1.002 respectively. The programme also reduced social discriminations before joining to PSNP, helped to drop out from local informal creditors who lend some amount of money to the poor households and receive the money with large interest rate. In general productive safety net programme/PSNP/ helped the households to participate with different social aspects with the total mean of 3.52 and standard deviation of 0.952 .

Table 4.12: Gender equality (women's participation)

\begin{tabular}{llrr}
\hline Women's participation & N & Mean & Standard Deviation \\
\hline Participation in planning of PSNP & 352 & 4.02 & .860 \\
BCC training and Decision making ability & 352 & 3.91 & .915 \\
Kebele Food Task Force committee membership & 352 & 3.81 & .997 \\
Using 'soft conditionality's"' of PSNP & 352 & 3.79 & 1.047 \\
\hline Total & & $\mathbf{3 . 8 8}$ & $\mathbf{0 . 9 5 4}$ \\
\hline
\end{tabular}

Source: Field survey data, 2020

Insuring gender equality is also foremost activity in productive safety net programme. According to the above table 4.12, the respondents were asked to answer whether they are participating or not in different levels of PSNP activities. The response shows women's participation in planning of PSNP the mean of 4.02 and standard deviation of 0.860 , followed by BCC training and decision making ability with the mean of 3.91 and standard deviation of 0.915 kebele food task force committee membership with the mean of 3.81 and standard deviation of 0.997 and finally the respondents were using soft conditionality's allowed of the programme manual with the mean and standard deviation of 3.79 and 1.047 respectively. From the above data we can refer that PSNP assisted gender equality mainstreaming with total mean of 3.88 and standard deviation of 0.954 .

Table 4.13: Community Health and Nutrition

\begin{tabular}{lllll}
\hline $\begin{array}{c}\text { Have you participated in community health and Nutrition } \\
\text { issues in PSNP? }\end{array}$ & $\begin{array}{c}\text { Yes } \\
\text { Frequency }\end{array}$ & $\begin{array}{c}\text { No } \\
\text { Percent }\end{array}$ & Frequency & Percent \\
\hline Participation in community health and nutrition activities & 222 & 63.07 & 130 & 36.93 \\
Understanding of Post and anti natal Health care services & 306 & 86.93 & 46 & 13.07 \\
Increased knowledge to Nutrition sensitive Agriculture & 244 & 69.32 & 108 & 30.68 \\
\hline
\end{tabular}

Source: House hold survey data, 2020

Table 4.13 analyzes community health and nutrition concepts. $63.07 \%$ of the respondents replied that they were participating in community health and nutrition sensitive issues, 36.93\% answered 'no' this question. $86.93 \%$ of participant responded that they do have better understanding of post and anti - natal health care services for women's, large portion of participants $(69.32 \%)$ increased knowledge to nutrition sensitive agriculture. The programme has been remarkable positive impact on health and nutrition issues.

\subsection{Key Challenges of PSNP in the three selected Districts}

The key challenges were analyzed by focused group discussion (FGDs) of the respondents. The respondents were full of beneficiaries of PSNP. Nine (9) focus group discussions (FDGs) one from each kebelle's were prepared and named by codes.

\subsubsection{Targeting challenges}

Focus group discussion (FGD1) in Lasho kebele ( sodo zuria districts) responded that targeting of PSNP was not according to program implementation manual, the manual says targeting households should be poor of poor, low 
land size (less than 0.025 ha) but most the safety net programme clients were not fulfilling the above mentioned criteria's. (FGD members, Lasho, 2020), The focus group discussant also replied that

"' The local kebele authority (leaders) were intentionally target some of their friends, relatives and those people who benefit the leaders indirectly, the targeting procedure is unknown for us, not clear, not in time, the leaders were retarget as they wish, there is invisible corruptions." (FGD2 members, Shasha Gale, 2020)

\subsubsection{Payments(transfer) challenges}

The program adopted technological system (electronic payments) in order to facilitate the problem cash transfer. All PSNP clients were listed in this payment list (PASS), but some obstacles were raised by the discussants such as lack of knowledge to PIN code, the payment was not on the time (timeliness of the payments), some unknown deductions from public work participants, insufficient cash transfer for our full families (FGD3 Members,Gacheno and Buge of D/Gale districts, Waja Kero of Sodo Zuria districts,2020)

\subsubsection{Weak appeal management}

The productive safety net program has its own appeal request system to the clients about the problem of selection, payments (transfers), credit access and the others. The respondents were asked to introduce the appeal request and management system and highlighted that

"There were no appeal systems to tell our problems regarding the program apart from kebele level, when we go to the higher levels districts (woreda, zones), local leaders don't want this, some of our neighbors' were reduced from the program unnecessarily or illegal by telling their problems, the appeals were not getting response on time, sometimes not managed totally, if there is system for us to ask and tell our questions it will be good for us". (FGD4 members, Dubo, 2020).

\subsubsection{Low economy base}

Even though productive safety net program selects poor households from the community, the focus group discussant noted that they persist with some challenges such as low land size, low capital amount (low amount of cash gaining from crop and livestock), low saving culture in aggregate, natural shocks shock due to the above challenges the clients economy base was falling down and made substantial challenge for households and due to this some of them were adapted to the program(FGD5,Buge,Shaha gale of D/Gale Districts,2020)

\subsubsection{Graduation}

It expected that the program clients at the end of the program years have to graduate from food security. The program has its own rule and procedure to graduation. The clients have to collect cash for three years continuously and at the final year the client has to be accessed with credit. According to this procedure the FGD members were asked to respond that their feelings to graduation and noted that actually our livelihood currently changed before we joining PSNP, but nowadays we have less ability to graduate, many problems we face such as food gap, clothing, children schooling, livestock feeding and we don't have enough money. The discussants were replied they were not happy to graduate. The reason for this is the criteria of graduation is not fulfilling (FGD Members,Dubo,Gurumo Koysha, Shasha Gale, 2020)

\section{Conclusions and recommendations}

\subsection{Conclusions}

The study analyzed the opportunities and challenges of Ethiopian Productive Safety Net Programme/PSNP4/.Accordingly, the major findings of the study were: the socio-demographic characteristics of the participants, the majority of the respondents were males $(59 \%)$, and $41.18 \%$ of the respondents were illiterate and $36.93 \%$ attended primary education, large portion $(78.41 \%)$ of the respondents were married, large percentage of the households (50.57\%) hold the family size range of 4-6,and $81 \%$ of the respondents have less than 0.25 hectare farmland.

Productive Safety Net Programme (PSNP) has a vast opportunity to the community. According to this study, the major opportunities of PSNP to the society are household and community level economic opportunities. At household level the economic opportunities are consumption payments, ownership of major home equipments and livestock's, consultations and financial literacy trainings, the beneficiaries become accustomed to saving, access to credit, accumulation of capital from PSNP, and at the community level the opportunities are the construction of communal ponds, farmers training center (FTC) construction, school expansion and health center construction are the majors. It is also concluded that the study assures social opportunities, gender equality (participation of females), community health and nutrition.

The key challenges when implementing at grass root level, weak targeting system, and payments (transfer) problems such as not paid on time (timeliness), low economy base, low level of graduation and low level of appeal management.

\subsection{Recommendations}

Based on the results obtained from the study, the following points are recommended:

The households, community and government of Ethiopia should keep up the economic and social 
opportunities of PSNP. The local administration should give attention to awareness in the community about the public works and their importance in advance.

- $\quad$ Targeting process should be implemented according to programme implementation manual, the kebele and woreda administrators have to collect the data before deciding who poor ane who is not is. To decide targeting effective recording of wealth of whole kebele members those are exist in the kebele. It should not be in some relations or other corruption assumptions. It is better the government should also collect the baseline data in the use of technological data management systems that minimizes the errors of targeting.

- The Payment of public work clients should be on the time, sufficient and fair. The woreda and zonal level authorities have to oversee the payment performance on the time and have to take a remedial actions to those body who suspected by illegal activities.

- To transform food insecurity to food security, it is advisable that the government has to increase support to those PSNP members who have low economy base by initiating other national and country wide projects in addition to PSNP.

- The appeal management system have to strengthen, the poor household have to told their feelings, problems and even can ask questions. The main of PSNP is graduation of poor households from food insecurity. Hence, graduation processes performance has to be renewed, should be based on the wealth ranking of each households.

\section{References}

1. Abebe, G., Franklin, S. and Mejia-Mantilla, C., 2018. Public works and cash transfers in urban Ethiopia: Evaluating the Urban Productive Safety Net Program.

2. Andersson, C., Mekonnen, A. and Stage, J., 2011. Impacts of the Productive Safety Net Program in Ethiopia on livestock and tree holdings of rural households. Journal of Development Economics, 94(1), pp.119-126.

3. Azadi, H., De Rudder, F., Vlassenroot, K., Nega, F. and Nyssen, J., 2017. Targeting International Food Aid Programmes: The Case of Productive Safety Net Programme in Tigray, Ethiopia. Sustainability, 9(10), p.1716.

4. Bickel, G., Nord, M., Price, C., Hamilton, W. and Cook, J., 2000. Guide to measuring household food security. Alexandria. Department of Agriculture Food and Nutrition Service.

5. CSA, C. S. A. (2013). Area and Production of Major Crops. Report on Area and Crop Productionforecast for Major Crops (For Private Peasant Holding, Meher Season.

6. CSA, C. S. A. (2016). Ethiopian Socio-Economic Survey

7. Desalegn, G. and Ali, S.N., 2018. Review of the Impact of Productive Safety Net Program (PSNP) on Rural Welfare in Ethiopia (No. 1547-2018-6243).

8. EEA. (2016). Report on the Ethiopian Economy.

9. FDRE. (2014). Productive Safety Net Programme 4. Addis ababa, Ethiopia: Ministry of Agriculture Disaster Risk Management and Food Security Sector.

10. Gilligan, D.O., Hoddinott, J. and Taffesse, A.S., 2009. The impact of Ethiopia's Productive Safety Net Programme and its linkages. The journal of development studies, 45(10), pp.1684-1706.

11. Hirvonen, K. and Hoddinott, J.F., 2018. Payment modality preferences: Evidence from Ethiopia's Productive Safety Net Programme (Vol. 125). Intl Food Policy Res Inst.

12. Legesse Debela, B., Shively, G. and Holden, S., 2019. Does Ethiopia's Productive Safety Net Program Improve Child Nutrition? (No. 1/14). Norwegian University of Life Sciences, Centre for Land Tenure Studies.

13. Hailu, G. and Ali, S., 2018. Review of the Impact of Productive Safety Net Program (PSNP) on Rural Welfare in Ethiopia.

14. Kassa,W. A, 2018. Impact of productive safety net program in rural community of Ethiopia: A review study: Vol.10(5), pp. 84-88, May 2018. Journal of Agricultural Extension and Rural Development.

15. Maxwell, S. and Smith, M., 1992. Household food security: a conceptual review. Household food security: Concepts, indicators, measurements, 1, pp.1-72.

16. Mohamed, A.A., 2017. Impact of Ethiopia's Productive Safety Net Programme (PSNP) on the Household Livelihood: The Case of Babile District in Somali Regional State, Ethiopia. International Journal of Economy, Energy and Environment, 2(2), p.25.

17. Paula A. Dorosh and Shahidur Rashid, 2012 Food and Agriculture in Ethiopia: Progress and Policy Challenges, International Food Policy Research Institute

18. Pinstrup-Andersen, P., 2009. Food security: definition and measurement. Food security, 1(1), pp.5-7.

19. Shigute, Z., Mebratie, A.D., Sparrow, R., Yilma, Z., Alemu, G. and Bedi, A.S., 2017. Uptake of health insurance and the productive safety net program in rural Ethiopia. Social Science \& Medicine, 176, pp.133- 
141.

20. Welteji, D., Mohammed, K. and Hussein, K., 2017. The contribution of Productive Safety Net Program for food security of the rural households in the case of Bale Zone, Southeast Ethiopia. Agriculture \& Food Security, 6(1), p.53.

\section{ACKNOWLEDGEMENTS}

The author special thanks go to Mr. Alemayehu Elda (Assistant professor) and Woreda and kebelle Food Security Office staffs for their technical assistance provided during review of different literature. 